\title{
Correlation between Dermatoglyphics, Dental Caries and Salivary pH: An Invivo Study
}

\author{
Tegginmani Veeresh $^{1^{*}}$, Ahmed Mujahid ${ }^{2}$, Patil Deepu $^{3}$, Reddy Sivaprakash $^{4}$
}

OPEN ACCESS

Citation: Tegginmani Veeresh, Ahmed Mujahid, Patil Deepu, Reddy Sivaprakash. Correlation between Dermatoglyphics, Dental Caries and Salivary pH: An Invivo Study. Ethiop J Health Sci. 2018;29 (1):929.

doi:http://dx.doi.org/10.4314/ejhs.v29i1.15 Received: May 07, 2018

Accepted: August 15, 2018

Published: January 1, 2019

Copyright: (C) 2018 Tegginmani V., et al. This is an open access article distributed under the terms of the Creative Commons Attribution License, which permits unrestricted use, distribution, and reproduction in any medium, provided the original author and source are credited.

Funding: Bona District Health Bureau and Abem private clinic.

Competing Interests: The authors declare that this manuscript was approved by all authors in its form and that no competing interest exists.

Affiliation and Correspondence:

${ }^{1}$ Department of Conservative Dentistry

and Endodontics, AME's Dental

College and Hospital, Raichur

*Email: dr.viresh@gmail.com

\author{
ABSTRACT
}

BACKGROUND: Dermatoglyphic patterns that are often utilized in judicial and legal investigations are valuable in diagnosis of many diseases related to genetic disorders. Caries, being infectious in origin, might be related to genetics as well. Hence, these patterns are of significance in predicting caries development.

MATERIALS AND METHODS: DMFT (decayed, missing, filled teeth) score of 300 female subjects within the age group of 18-25 years were recorded and accordingly divided into 3 groups of 100 each; group 1 (DMFT score=0), group 2 (DMFT score < 5) and group 3 (DMFT score $\geq 5$ ). Dermatoglyphic patterns were recorded using Cummins and Midlo method. $\mathrm{pH}$ meter was used for recording salivary $\mathrm{pH}$ accurately. Fingerprint patterns and salivary $\mathrm{pH}$ recorded were correlated with DMFT scores of subject and control groups. Statistical analysis was performed using ANOVA and Chi-square tests $(P<0.05)$.

RESULTS: The mean salivary $\mathrm{pH}$ was least in group 3. The predominant dermatoglyphic pattern observed in groups 1 and 2 was loop pattern whereas, in group 3, whorl pattern was predominant. The TFRC (total finger ridge count) was higher in group 3 compared to the other two groups.

CONCLUSION: Caries-free people showed inflated frequency of loops, whereas subjects with high decayscore had additional share of whorls. The TFRC was higher in individuals with high DMFT score, and salivary $\mathrm{pH}$ was inversely proportional to the DMFT score.

KEYWORDS: Dermatoglyphics, Dental caries, pH

\section{INTRODUCTION}

Dental caries is an outcome of the interaction between certain dependent factors such as host, agent and environment. This process of caries occurrence includes demineralization of enamel and/or dentin which is pretty much dependent on $\mathrm{pH}$ of saliva. Various methods of diagnosis are devised clinically to quantify caries process qualitatively and one circumspect parameter for same is dermatoglyphics. 
"Dermatoglyphics" is derived from Greek words "Dermato" means skin and "Glyphics" means carving. Dermatoglyphics refers to permanent imprint patterns of epidermal ridges on palmar and plantar surfaces of hands and feet respectively. Ridge pattern study popularly called "Samudra Shastra" has been followed in India since ancient times classified imprints of hands and feet into "Chakra, Shankya and Padma" that corresponds with the whorl, loop and arch patterns of contemporary classification (1).

The first person to study dermatoglyphics was Grew in 1684. Parkinjee classified epidermal ridge patterns into nine types in 1923 (2). In India, William Herschel (1880) used fingerprints for personal identification of individuals (1). Many investigations revealed dermatoglyphic variations between normal individuals and patients with chromosomal aberration like trisomy 8, trisomy 13 and trisomy 18 (2). Sharma et al., and Kharbanda et al., found correlation of dermatoglyphics in mandibular prognathism and retrognathism cases $(3,4)$. Many studies have shown the relationship between dermatoglyphic patterns and illnesses like Down's syndrome, Alzheimer's disease, multiple sclerosis $(5,6)$, congenital defects like cleft lip and cleft palate (7), periodontal diseases, bruxism, malocclusion (8) and oral submucous fibrosis $(9,10)$.

Studies have proved that dermatoglyphics helps in preventing diseases, for detecting intrauterine anomalies and identifying diseases like breast carcinoma, type I diabetes mellitus, etc (1). This relation between variations in dermatoglyphics and numerous diseases and/or syndromes can be credited to the actual fact that morphogenesis of epidermal ridges and organogenesis occurs at same period during embryogenesis and programmed by genetic expressions which are related to each other $(7,11,12)$.

Dental caries has multiple interlinked etiopathological components, and its relationship with epidermal ridges is explained by the fact that the teeth and dermal ridges develop from same germ layer ectoderm during the same time period of $6^{\text {th }}$ to $7^{\text {th }}$ week of intrauterine life. It contains genetic information which are interrelated, and any disturbance seen during this period reflects on each other (13). Thus, this study was conducted to evaluate if any correlation exists between dermatoglyphics and dental caries. Evaluation of salivary $\mathrm{pH}$ in causation of dental caries has been much studied previously but was revisited in this study to ascertain the correlation.

\section{MATERIALS AND METHODS}

A cross-sectional study was performed according to the ethical principles of the Declaration of Helsinki, with institutional ethical clearance registration number AME/DC/276/2017-18. Three hundred female patients aged between 18-25 years, who reported to the Outpatient Department were included in the study. The purpose of the study was explained, and written inform consent was obtained for the same. Unwilling patients, patients who were unable to record their finger prints due to trauma, skin abnormalities etc., dental fluorosis, individuals and patients with poor oral hygiene with OHI-S (oral hygiene index simplified) (14) score of $\geq 3$ were excluded from the study.

DMFT (decayed, missing, filled teeth) index was used to record the caries status of the individuals. Careful evaluation of caries was done by using sterilized right-angle probe (no.17), shepherd probe (no.23) and odontoscope. The salivary $\mathrm{pH}$ of the respective subject was recorded by immersing the tip of Digital $\mathrm{pH}$ meter (Erma $\mathrm{Ph}-035$ professional meter, $\mathrm{pH}$ resolution 0.01 ) in unstimulated saliva which was collected two hours after food in a sterile container. Three hundred subjects were selected based on DMFT score and grouped into three of 100 each: Group 1 , DMFT score $=0$; Group 2, DMFT score $<5$ and Group 3, DMFT score $\geq 5$.

Method of recording finger prints: Dermatoglyphic patterns on all 10 palmar digits of each individual were recorded using Cummins and Midlo (1943) method as follows. First, the hands of the subjects were cleaned thoroughly and

DOI: http://dx.doi.org/10.4314/ejhs.v29i1.15 
dried. After this, finger prints of right and left hands were recorded where the examiner guided the subjects to press the finger tips against ink stamp pad and then onto the bond paper (9). If the recorded prints were not clear, the procedure was repeated. From 300 subjects, 3000 finger prints (10 per individual) were recorded.

Evaluation of fingerprint patterns: Dermatoglyphic patterns were analyzed using magnifying lens (X2 magnification). Three basic or parental patterns of dermatoglyphics which include whorl, loop and arch patterns were assessed. Additionally, evaluation of triradius and total finger ridge count (TFRC) were also done.

Whorls are seen as epidermal ridges in circle or spiral shape which has various subtypesconcentric whorl, spiral whorl, elongated whorl, composite whorl, double loop whorl, imploding whorl, peacock's eye whorl and variant whorl. Loops have epidermal ridges which start from one side of the finger, elevate or form loop towards center and return back to same side. Based on the bone towards which loop faces subdivisions include ulnar loop and radial loop. In arch pattern, the epidermal ridges start from one side of the finger form, elevates at the center forming arch and leave towards opposite side. Based on the shape of the arch, it is of 2 types, simple or low arch and tented or high arch (Figure 1).

In our study, subgroups of all the patterns were designated and recorded as their respective parent pattern. Triradius is a triangular part formed Table 1: Distribution of groups based on dermatoglyphic patterns

\begin{tabular}{llll}
\hline & $\begin{array}{l}\text { GROUP 1 } \\
(\text { DMFT=0) }\end{array}$ & $\begin{array}{l}\text { GROUP 2 } \\
(\text { DMFT<5) }\end{array}$ & $\begin{array}{l}\text { GROUP 3 } \\
\text { (DMFT } \geq 5)\end{array}$ \\
\hline whorl patterns & $17 \%$ & $15 \%$ & $\mathbf{6 5 \%} \%$ \\
loop patterns & $\mathbf{7 4 . 5 \%}$ & $\mathbf{7 4 . 5 \%}$ & $34 \%$ \\
arch patterns & $8.5 \%$ & $10.5 \%$ & $1 \%$ \\
\hline
\end{tabular}

\section{DISCUSSION}

Dental caries is one of the most prevalent chronic diseases seen worldwide. Individuals are susceptible to decay throughout their lifetime (15). Multifactorial etiology defines the causation by epidermal ridges from three directions which meet at a point forming an angle of $120^{\circ}$ with each other. The total number of epidermal ridges from the center or core of dermatoglyphic pattern to the triradius of each finger accounts for TFRC (1) (Figure 2).

Dermatoglyphic patterns were analyzed thrice, and the mean results were evaluated statistically using SPSS software (version 22.0 SPSS Inc., Chicago, USA). ANOVA and Chisquare tests were employed for correlating the parameters. $P$ value $<0.05$ was considered as statistically significant.

\section{RESULTS}

All the individuals evaluated had good to fair oral hygiene status. In all the three groups analyzed, the mean salivary $\mathrm{pH}$ was $7.5(0.3)$ in group 1 ; $7.5(0.4)$ in group 2 and $6.8(0.3)$ in group 3 $(p=0.001)$ (Figure 1A). The predominant dermatoglyphic pattern seen in group1 $($ DMFT $=$ $0)$ and group $2($ DMFT $<5)$ was loop pattern. Both groups had $74.5 \%$ of loop patterns whereas group 3 (DMFT $\geq 5$ ) had $34 \%$. Whorl patterns were seen most commonly in group $3(65 \%)$ followed by group 1 and group 2 with $17 \%$ and $15 \%$ respectively $(p=0.002)$ (Table 1$)$. The TFRC was higher in group 3 [121.2(SD 21.6)] compared to group 1 [80.5(SD 21.2)] and group 2 [101.1(13.8)], which was statistically significant $(P<0.05)$ (Figure 3B). 


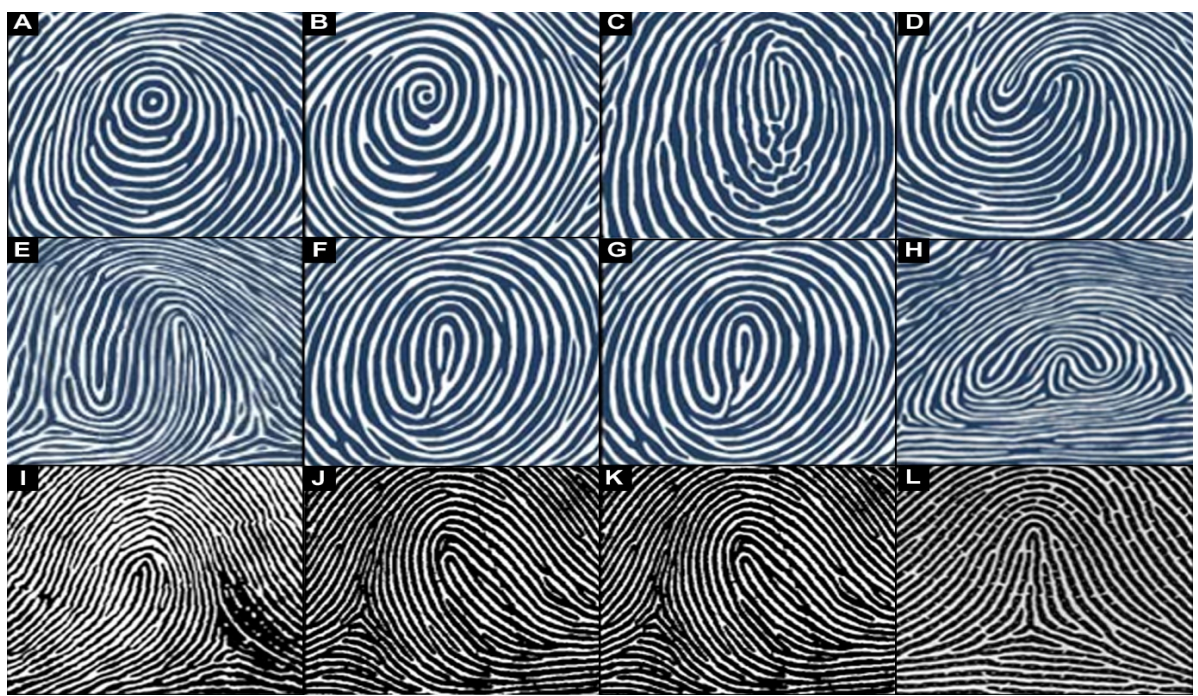

Figure 1: A-Concentric whorl, B-spiral whorl, C-elongated whorl, D-composite whorl, E-double loop whorl, F-imploding whorl, G-peacock's eye whorl, H-variant whorl, I-ulnar loop, J-radial loop, K-Low arch, L-high arch

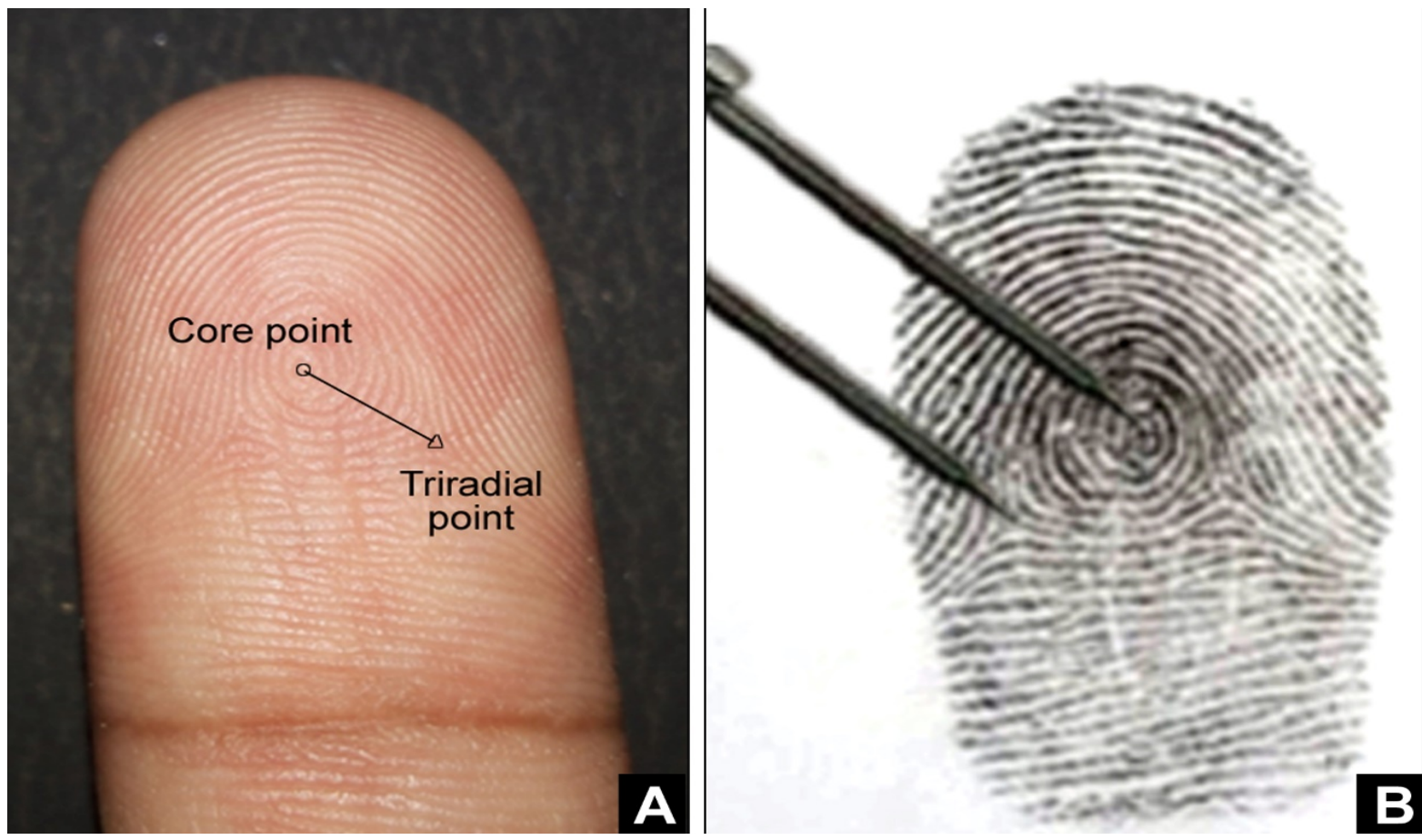

Figure 2: A-Core and triradus in pattern, B-Measurement of total number of epidermal ridges between core and triradius(TFRC) 

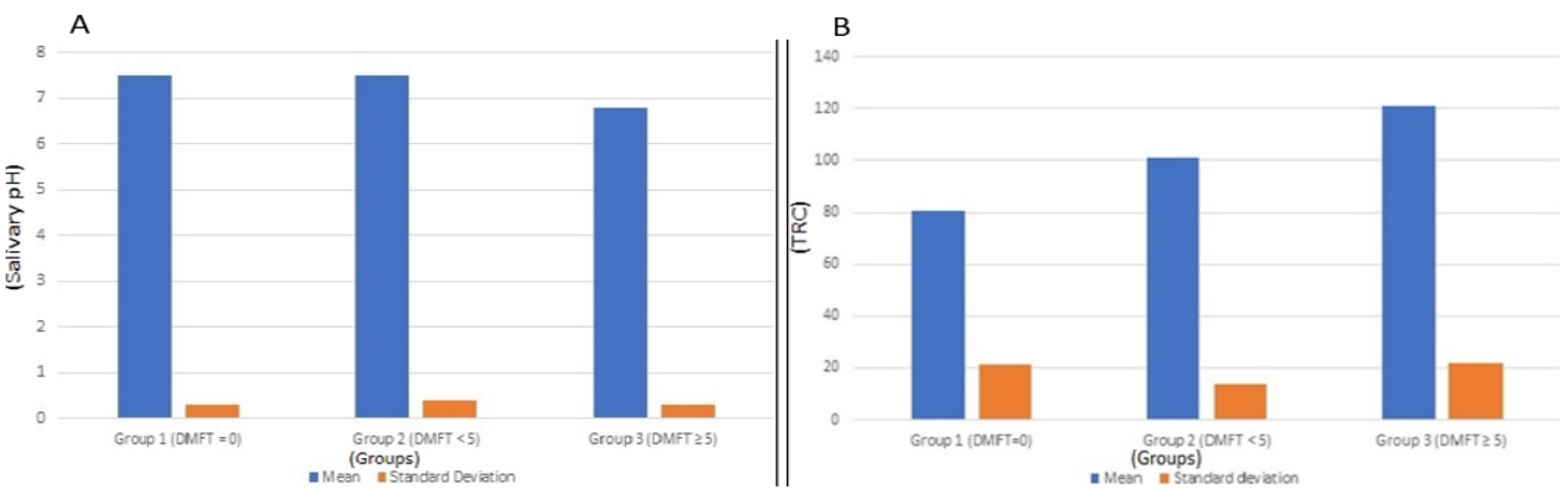

Figure 3: A-Distribution of the groups based on salivary $\mathrm{pH}$ ( $x$-axis represents groups and $y$-axis represents salivary pH. B-Distribution of the study groups based on TRC (x-axis represents groups and y-axis represents TRC)

Dermatoglyphic patterns are unique for every individual which remains unchanged once formed. Thus, it is used as biometric analyzer for identification of individuals and also used for recognizing particular diseases/syndrome in preventive medicine (1).

In this study, two important etiological variables of caries which include genetic component and host factor corresponding to dermatoglyphics and salivary $\mathrm{pH}$ respectively were studied.

On dermatoglyphical analysis, loop patterns were most commonly observed in the control group $(\mathrm{DMFT}=0)$, whereas, in high caries group $(\mathrm{DMFT} \geq 5)$, whorl patterns were seen most. The TFRC were more in subjects with high caries than in the control subjects, suggesting the genetic correlation. The salivary $\mathrm{pH}$ was comparatively lower in high caries group than in cariesfree group, as analyzed in other studies (17) indicating the importance of host factor in causation cascade.

Dermal ridges originate from fetal volar pads that appears during the $6-7^{\text {th }}$ week of intra-uterine life, which corresponds to the same period as that of tooth formation in embryo. This suggest that the genetic message contained in the genome (normal or abnormal) is deciphered during this period and is reflected in both teeth and dermal ridges (18). The dermatoglyphics like whorl and loop patterns reflects the genetic susceptibility and proneness for dental caries due to abnormality in tooth structures (environmental factors) like alteration in enamel, tooth eruption and development. Hence, dermatoglyphics could indicate genetic susceptibility to dental caries $(19,20)$.

Individuals have a specific immunoglobulin within saliva who were highly resistant to dental caries which conveys the immunity by lysis of the cariogenic bacteria, and this phenotype is inherited and transmitted as an autosomal dominant trait (20). Thus, genes and genetic abnormality which lead to impaired structural organization of teeth and its environment results in increased susceptibility to dental caries (21). It is believed that caries prevalence is more in females than in males (22). Hence, in our study, only female subjects were included.

Previous studies $(11,23,24,25)$ were done in children of 3-6 years of age where correlation between genetic component and environmental factor in causation of caries were summarized and concluded as predominance of the former. In our study, subjects within the age group of 18-25 years were included with fair to good oral hygiene which eliminated the interference of possible environment component thereby highlighting the genetic component for evaluation.

Our study is in accordance with studies $(11,24,25)$ which showed increased frequency of ulnar loop and lower number of whorl patterns in low caries subjects. In another study (25), ulnar loop patterns were most in caries-free people, and subjects with caries index value of above 10 had more number of whorls on their fingertips which is in agreement with the findings of this study. However, our findings do not corroborate with the results of Akyuz which concluded that loop patterns were seen most in individuals with high DMFT score(26).

In this study, when dermatoglyphic patterns were evaluated individually, a person with loop patterns in all the 10 fingers had higher caries index value while a person with whorl patterns in eight fingers remained caries-free. Similarly, an individual having acidic salivary $\mathrm{pH}$ remained caries-free and the one with basic $\mathrm{pH}$ had DMFT score of $>5$. Thus, the multifactorial etiology of dental caries is provable, and all the factors should be in the mind of a clinician during diagnostic and preventive procedures in caries management.

Within the limitations of this study, the mean

DOI: http://dx.doi.org/10.4314/ejhs.v29i1.15 
salivary $\mathrm{pH}$ was lower in high caries individuals. Loop patterns were seen commonly in caries free persons, whereas whorl patterns were common in individuals with high DMFT score. The TFRC was higher in high DMFT score individuals. This clearly indicates that genetic parameter can be used to quantify dental caries, thereby helping in its prevention.

\section{REFERENCES}

1. Prathibha R, Abhilash PR, Sherlin HJ, Anuja N, PremkumarP,Chandrasekar T, et al. Conventional dermatoglyphics - Revived concept: A review. Int J Pharma Biosci 2011;2: B446-58.

2. Qazi QH, Masakawa A, McGann B, Woods J. Dermatoglyphic abnormalities in the fetal alcohol syndrome. Teratology 1980; 21:157-60.

3. Sharma VP, Gupta DS, Kharbanda OP. Dermatoglyphic evaluation of retrognathism. $J$ Indian Dent Assoc 1980; 52:111-4.

4. Kharbanda OP, Sharma V, Gupta DS. Dermatoglyphic evaluation of mandibular prognathism. J Indian Dent Assoc 1982; 54:179-86.

5. Baca OR, Del Valle Mendoza L, Guerrero NA. Dermatoglyphics of a high altitude Peruvian population and interpopulation comparisons. High Alt Med Biol 2001; 2:31-40.

6. Cvjeticanin M, Polovina A. Quantitative analysis of digitopalmardermatoglyphics in male children with central nervous system lesion by quantification of clinical parameters of locomotor disorder. Acta Med Croatica 1999; 53:5-10.

7. Mathew L, Hegde AM, Rai K. Dermatoglyphic peculiarities in children with oral clefts. $J$ Indian Soc PedodPrev Dent 2005; 23:179-82.

8. Tikare S, Rajesh G, Prasad KW, Thippeswamy V, Javali SB. Dermatoglyphics: A marker for malocclusion? Int Dent J 2010; 60:300-4.

9. Tamgire DW, Fulzele RR, Chimurkar VK, Rawlani SS, Sherke AR. Qualitative dermatoglyphic analysis of fingertip patterns in patients of oral submucous fibrosis. IOSR J Dent Med Sci 2013; 6:24-7.

10. Prabhu N, Issrani R, Mathur S, Mishra G, Sinha S. Dermatoglyphics in health and diseases: A review. J Res Adv Dent 2014; 3:20-6.

11. Madan N, Rathnam A, Bajaj N. Palmistry: a tool for dental caries prediction! Indian $J$ Dent Res 2011; 22:213-8.

12. Kimura S. Embryologic development of flexion creases. Birth DefectsOrig Artic Ser 1991; 27:113.

13. Trehan M, Kapoor DN, Tandon P, Sharma VP.
Dermatoglyphic study of normal occlusion and malocclusion. J. Ind. Orthod. Soc 2000; 33:11-6.

14. Yamunadevi A, Dineshshankar J, Banu S, Fathima $\mathrm{N}$, Ganapathy, Yoithapprabhunath TR, et al. Dermatoglyphic patterns and salivary $\mathrm{pH}$ in subjects with and without dental caries: A crosssectional study. J Nat Sc Biol Med 2015; 6:295-9.

15. Selwitz RH, Ismail AI, Pitts NB. Dental caries. The Lancet 2007 Jan 12;369(9555):51-9.

16. Mukherjee DP. How Scientists read palms. Sci Today 1980:15-21.

17. Sengupta Ab, Bazmi BA, Sarkar S, Kar S, Ghosh C, Mubtasum H. A cross sectional study of dermatoglyphics and dental caries in Bengalee children. J Indian Soc PedodPrev Dent 2013; 31:245-8.

18. Madan N, Rathnam A, Bajaj N. Palmistry: A tool for dental caries prediction! Indian J Dent Res2011 Mar 1;22(2):213.

19. Hassell TM, Harris EL. Genetic influences in caries and periodontal diseases. Crit Rev Oral Biol Med 1995 Oct;6(4):319-42.

20. Bretz WA, Corby PM, Schork NJ, Robinson MT, Coelho M, Costa S, Melo Filho MR, Weyant RJ, Hart TC. Longitudinal analysis of heritability for dental caries traits. $J$ Dent Res 2005 Nov;84(11):1047-51.

21. Walker NF. The use of dermal configurations in the diagnosis of mongolism. $J$ Pediatr1957 Jan 1;50(1):19-26.

22. Sivapathasundharam B, Raghu AR. Dental caries. In: Rajendran R, Sivapathasundharam B, editor. Shafer's textbook of oral pathology, $6^{\text {th }}$ ed. Noida: Elsevier; 2009. P. 409-73.

23. Bhat P, Badiyani B, Aruna CN, Chengappa S, Bhaskar N. Dermatoglyphics - A new diagnostic tool in detection of dental caries among deaf and mute children. Int J Clin Dent Sci 2011; 2:80-4.

24. Sharma A, Somani R. Dermatoglyphic interpretation of dental caries and its correlation to salivary bacteria interactions: an in vivo study. $J$ Indian Soc PedodPrev Dent 2009; 27:17-21.

25. Atasu M. Dermatoglyphic findings in dental caries: a preliminary report. J Clin Pediatr Dent 1998; 22:147-9.

26. Akyuz S. Hemifacial microsomia. Oral, clinical, genetic and dermatoglyphic findings. J Clin Pediatr Dent 1998; 23:63-8. 